\title{
O Paradoxal Regime de Crescimento Brasileiro no Período Pré- Plano Real
}

\section{The Paradoxical Brazilian Growth Regime in Pre Real Plan Period}

\begin{abstract}
Arthur Brackmann Netto ${ }^{a}$
Resumo: É frequente o debate quanto à efetividade das políticas neoliberais implementadas após o Plano Real. Entretanto, o regime de crescimento da economia é, quando muito, apenas suposto, não passando por validação empírica. Desse modo, busca-se, com o uso do referencial kaleckiano, testar empiricamente o regime de crescimento da economia brasileira antes da implantação do Plano Real, com o objetivo de dar embasamento ao debate. Encontra-se, de acordo com o modelo apresentado por Bhaduri e Marglin (1990), uma estrutura doméstica profit-led e uma estrutura total wage-led, resultados peculiares quando contrastados com a literatura, porém condizentes com fatos históricos e a teoria. Essa peculiaridade é destacada pelo fato de que nos testes empíricos a propensão a consumir de trabalhadores e capitalistas não pôde ser distinguida, como frequentemente assumido na teoria pós-keynesiana.
\end{abstract}

Palavras-chave: Modelos kaleckianos. Wage-led. Regime de crescimento. Brasil

\begin{abstract}
The debate regarding the effectiveness of neoliberal policies implemented after the Real plan is a Brazilian cliché. However, the economic growth regime is, when commented, just supposed, not passing by empirical validation. Therefore, the work searches - using kaleckian references - to test empirically the economic growth regime of the Brazilian economy before the implementation of the Real plan. The objective is of offering empirical support for the debate. It was found, following Bhaduri and Marglin's (1990) model, a profit-led domestic structure and a wage-led total structure, peculiar results when contrasted with the literature, nevertheless consistent with historical facts and theory. This peculiarity was highlighted by the fact that in the empirical tests the propensity to consume of workers and capitalists could not be distinguished as is often assumed in postKeynesian theory.
\end{abstract}

Keywords: Kaleckian models. Wage-led. Growth regime. Brazil.

JEL Classification: C13; E12; E25; O11.

\section{Introdução}

Kalecki, com o princípio da demanda efetiva e suas suposições quanto às propensões a consumo das classes trabalhadora e capitalista, iniciou uma tradição de formalização de modelos, relacionando distribuição funcional da renda e cres-

a Universidade de São Paulo (USP), Departamento de Economia. São Paulo, Brasil. 
cimento. Com base nos preceitos kaleckianos, os resultados teóricos iniciais de Rowthorn (1982) e Dutt (1984) indicam que o crescimento das economias era única e exclusivamente wage-led, posto que os efeitos de demanda proporcionados por elevações salariais eram considerados superiores aos seus efeitos de custo.

Bhaduri e Marglin (1990), entretanto, alteram as formulações teóricas de forma que aumentos da parcela salarial na renda podem ter efeitos tanto negativos quanto positivos no crescimento das economias. Essas, desse modo, podem ter regimes de crescimento tanto profit-led quanto wage-led. O primeiro ocorre quando os efeitos de custos dos salários superam os efeitos de demanda e o segundo, no caso contrário. Torna-se, dessa maneira, uma questão empírica se as economias crescem com mais salários ou com mais lucros e se inicia uma tradição de mensuração econométrica dos regimes de crescimento. Além dessa vertente mais empírica, é interessante destacar que o modelo continuou sendo modificado teoricamente, com extensões sraffianas ${ }^{1}$ e harrodianas, ${ }^{2}$ por exemplo. ${ }^{3}$ Nessas, o resultado profit-led não necessariamente foi incluído, o que as libera de testes empíricos para validar os regimes de crescimento.

À tradição econométrica se soma o fato de que as políticas adotadas pelos países também podem ser divididas em profit-led ou wage-led. Lavoie e Stockhammer (2012) dividem essas políticas entre pró-trabalho e pró-capital, a primeira wage-led e a segunda profit-led. De acordo com a tradição kaleckiana, a interação entre política e regime está no centro da trajetória de crescimento das economias. Uma política pró-capital em uma estrutura wage-led gera um crescimento instável ou recessões, o mesmo acontece para o caso oposto - políticas pró-trabalho e uma estrutura profit-led. Quando política e estrutura estão em consonância os países apresentam crescimentos estáveis e mais elevados.

No caso brasileiro, é frequente o debate quanto à efetividade das políticas neoliberais implementadas após o plano real. Entretanto, apesar da tradição iniciada por Bhaduri e Marglin, o regime de crescimento da economia é, quando muito, apenas suposto, não passando por validação empírica. Assim, mesmo entre a literatura pós-keynesiana, o debate é ocasionalmente inócuo, posto que não leva em consideração o fato de que regimes de crescimento são uma questão empírica e não teórica. Duas correntes de pensamento surgem com destaque no debate brasileiro predominantemente teórico: novo-desenvolvimentistas e sociodesenvolvimentistas. ${ }^{4}$ A partir das características macroeconômicas brasileiras, a primeira defende uma política export-led, que, em sua essência, se identifica com

$1 \quad$ Ver Serrano (1995).

2 Ver Skott (1989).

3 Ver Hein (2014) e Lavoie (2015) para uma revisão teórica das principais extensões dos modelos pós-keynesianos de crescimento de longo prazo.

Ver Bresser-Pereira (2012) para uma discussão dos pontos centrais do novo-desenvolvimentismo e Bielschowsky (2012) para argumentos em favor do social-desenvolvimentismo. 
o regime profit-led, enquanto a segunda propõe políticas wage-led. ${ }^{5}$ Destacando o caráter pouco empírico das discussões, reside o fato de que o caso brasileiro ainda foi pouco estudado através de métodos quantitativos. Nesse sentido, foram revisados apenas seis trabalhos com testes para a economia brasileira, quais sejam: Bruno (2003), Tomio (2012), Araújo e Gala (2012), Câmara, Feijó e Cerqueira (2013), Oreiro e Araújo (2012) e Oreiro, Abramo e Lima (2013).

Os resultados desses trabalhos divergem significativamente, o que impede qualquer conclusão sobre o regime de crescimento da economia brasileira a partir da análise apenas desses trabalhos. Seguindo a literatura internacional, no entanto, é sabido que: a) economias fechadas tendem a ser wage-led; b) quanto maior o território, maior a chance de o país ser wage-led; c) dependência externa, como fonte de demanda, propicia regimes profit-led. Por essa perspectiva, mensurações econométricas - ainda que com seus defeitos - continuam necessárias para que sejam realizadas as comparações devidas entre características estruturais das economias e políticas econômicas, assim como para entender o caso brasileiro dentro dos resultados esperados pela literatura.

Desse modo, propõe-se verificar o regime de crescimento da economia brasileira antes da implementação do pleno real, no período de 1950 até 1994. Com isso, pretende-se dar bases para o estudo dos impactos das políticas efetuadas após esse período, bem como para entender o caso brasileiro frente aos resultados esperados.

Este trabalho se divide da seguinte maneira: a segunda seção expõe o modelo teórico que serve de base para o estudo empírico; a terceira seção apresenta uma revisão dos resultados empíricos das literaturas nacional e internacional; a quarta seção demonstra o modelo econométrico utilizado, seu método e resultados; a quinta seção traça as considerações finais.

Os resultados do trabalho surpreendem dado que o Brasil não se encaixa nas conclusões previstas pela literatura. Paradoxalmente, o país se opõe aos resultados mais básicos, inclusive contestando o recorrente pressuposto kaleckiano de que capitalistas têm uma propensão a poupar maior do que trabalhadores.

Dois pontos devem ser ressaltados antes de iniciar a discussão. Primeiro, o modelo kaleckiano utilizado no presente trabalho tem como pressuposto a existência de capacidade ociosa ao longo do tempo. Aceita-se tal suposição, dando base para os testes empíricos, por duas razões históricas. Primeiro, devido ao processo de substituição de importações ocorrido em boa parte do período analisado. As nuances do processo ao longo do período são inúmeras e em certo sentido o pressuposto implícito é o de que havia uma homogeneidade em torno do núcleo

5 Ver Mollo e Amado (2015) para uma discussão sobre social-desenvolvimentismo e novo-desenvolvimentismo dentro do escopo teórico de modelos pós-keynesianos. 
duro do conceito de desenvolvimentismo $0^{6}$ no período analisado. Este garantia às empresas a capacidade de expansão, bem como mercados que em outras circunstâncias não existiriam, sendo possivelmente um processo oligopolizador - o que faz com que a teoria de Kalecki (1954) se encaixe no caso brasileiro. Segundo, na sequência do período de substituição se seguiu um período de recessão econômica, especialmente na década de 80 . Uma recessão naturalmente leva à desutilização de capacidade e, portanto, à existência de capacidade ociosa. Assim, não se observa plena utilização de capacidade que justifique o uso de outro referencial teórico. Caso não se aceite tal hipótese, existe a necessidade de encontrar um modelo mais adequado.

Em segundo lugar, cabe destacar que se terá como suposto que a estrutura da economia não se alterou significativamente durante o período analisado ${ }^{7}$. Por tal afirmação entende-se que no que diz respeito ao comportamento do investimento, do consumo e das exportações em relação à distribuição de renda, não houve alterações significativas. Capitalistas e trabalhadores se comportaram de forma homogênea no período e seu comportamento não se alterou com o uso das políticas implementadas. Essa suposição é necessária para a realização da mensuração de um regime de crescimento, dado que é um desenho estático das características da economia do período.

É notável que o período é extenso, o que pode comprometer o uso dessa suposição. Porém, como suposto anteriormente, a homogeneidade é baseada na racionalidade pró-desenvolvimento que vigorou em boa parte do período analisado, com a possível exceção dos anos 80. Além disso, restrições técnicas e teóricas obrigam essa suposição. Primeiro, não foram realizados até o momento trabalhos investigando a extensão e estabilidade dos regimes de crescimento. Dessa forma, no presente trabalho assume-se que a estrutura da economia é estável durante décadas, uma suposição que pode vir a ser contestada tanto teórica quanto empiricamente. Segundo, inexistem séries trimestrais ou mensais dos dados necessários para a mensuração do regime brasileiro. Por conseguinte, é preciso estender o período por questões estatísticas. Desse modo, não é negada a possibilidade de que regimes de crescimento tenham extensões inferiores a quatro décadas. Nesse sentido, o regime encontrado pode ser interpretado como um resultado médio ou de longo prazo para o período em questão, visto que pode ter vivido ciclos curtos distintos (tanto wage-led, quanto profit-led).

$6 \quad$ Ver Fonseca (2015).

7 Apesar de frequentemente negligenciado na literatura empírica pós-keynesiana, esse pressuposto remete à crítica de Lucas (1976) e é essencial em modelos que propõem políticas públicas. Para críticas aos modelos de regimes de crescimento que levem em consideração as ponderações de Lucas, ver Palley (2014) e Skott (2017). 


\section{A Teoria dos Regimes de Crescimento}

Os modelos pós-keynesianos de distribuição e crescimento, bem como a própria teoria pós-keynesiana estão estruturados em torno do princípio da demanda efetiva. Este surgiu em discordância à lei de Say, que postula, resumidamente: "a oferta cria sua demanda". A aceitação dessa colocação tem diversas implicações na teoria econômica.

Caso a lei de Say se sustente e a oferta realmente crie demanda ex nihilo, os capitalistas possuem incentivos para investir quantidades adicionais até que o retorno de uma unidade adicional de investimento deixe de ser rentável. O consumo é garantido, uma vez que não existe restrição de demanda. Desse modo, a economia alcança um equilíbrio com plena utilização da capacidade produtiva, no qual todos os recursos são utilizados de acordo com sua produtividade marginal. Dessa forma, a poupança da economia, observada como a oferta de bens de capital, deve igualar e determinar a demanda por bens de capital, o investimento. Assim, aceitando o postulado de Say, poupança e investimento são idênticos, e a primeira determina o segundo.

Porém, retornando ao PDE, tem-se a inversão da lei de Say. Segundo Possas (2001), o PDE é simplesmente uma "antilei de Say" que coloca a demanda no centro da teoria. Isso ocorre, pois a única decisão autônoma na economia é a decisão de gastar. Com isso, o gasto determina a produção e, por conseguinte, a oferta é determinada pela demanda. Logo, investimento como decisão de gasto é autônomo. A poupança, por outro lado, é o resultado residual de todos os gastos efetuados. Então, poupança e investimento são funções distintas com propriedades próprias.

Assim, o modelo pós-keynesiano teórico a ser apresentado se sustenta na independência das decisões de gasto e, por consequência, na distinção das funções de investimento e poupança. Além disso, uma vez que o modelo representa uma economia aberta, expõe-se o comportamento das exportações líquidas, componente autônomo da demanda agregada. Portanto, o modelo teórico é definido por três partes distintas: o comportamento da poupança, do investimento e do setor externo. Por fim, unem-se os três com o objetivo de observar seu comportamento conjunto no longo prazo.

Tendo em vista a vasta literatura relacionada às formulações teóricas dos modelos kaleckianos, ${ }^{8}$ optou-se pela apresentação menos usual do modelo neokaleckiano de crescimento e distribuição, como observado por Stockhammer (1999). Consequentemente, o modelo exposto não faz uso das derivações a partir do mark-up de Kalecki. Com isso, pretende-se ganhar em simplicidade e brevidade,

8 Ver por exemplo: Bhaduri e Marglin (1990), Bertella (2007), Hein (2014), entre outros. 
porém mantendo em vista as perdas relacionadas aos possíveis insights referentes à formulação mais completa do modelo.

\subsection{Poupança}

A função poupança possui grande homogeneidade nos modelos pós-keynesianos, sendo comumente referida como equação de Cambridge. Segunda essa, a poupança, como função residual dos gastos, pode ser definida a partir das propensões a poupar dos agentes, como segue:

$$
\mathrm{S}=\mathrm{s}_{\mathrm{w}} \mathrm{W}+\mathrm{s}_{\mathrm{p}} \mathrm{P}
$$

A poupança, $\mathrm{S}$, é igual à propensão a poupar da classe trabalhadora, $\mathrm{s}_{\mathrm{w}}$, multiplicada pelos salários, W, mais a propensão a poupar da classe capitalista, $\mathrm{s}_{\mathrm{p}}$, multiplicado pelos lucros, P. Assumindo, de forma kaleckiana, que os trabalhadores gastam tudo o que ganham, tem-se uma propensão a poupar da classe trabalhadora nula e deste modo:

$$
S=s_{p} P
$$

Assim, a poupança da economia é inteiramente resultado dos gastos dos capitalistas. ${ }^{9}$ Normalizando a equação 2, dividindo pelo estoque de capital, obtém-se:

$$
\frac{S}{K}=\frac{s_{p} P}{K}
$$

Denotando $\frac{S}{K}=\mathrm{g}_{\mathrm{s}}$ e posto que o total dos lucros, $P$, dividido pelo estoque de capital, $K$, é a própria definição de taxa de lucro, $r$, tem-se:

$$
g_{s}=s_{p} r
$$

Assim, a taxa de crescimento da poupança, $g_{s}$, é igual à propensão a poupar da classe capitalista multiplicada pela taxa de lucros, $r$,. Por fim, sabendo-se que $r=\frac{Y P}{K Y}=u \pi^{10}$, tal que $\frac{Y}{K}=u$, produtividade do capital interpretada como taxa de capacidade utilizada, $\mathrm{e} \frac{P}{Y}=\pi$, profit-share, podemos reescrever a equação como:

9 Faz-se necessária apenas a suposição de que trabalhadores possuem uma propensão a poupar inferior à classe capitalista para alcançar os mesmos resultados, entretanto tal suposição tornaria o modelo mais complexo sem agregar conclusões úteis ao presente trabalho.

10 Formalmente e de forma mais completa, $r=\frac{P Y_{p} Y}{K Y_{p} Y}=\frac{P Y Y_{p}}{Y Y_{p} K}=\pi \mu \rho$, tal que $\frac{P}{Y}=\pi$ é o profit-share; $\frac{Y}{Y_{p}}=\mu$ é a medida de capacidade utilizada e $\frac{Y_{p}}{K}=\rho$ é a produtividade potencial do capital. Entretanto, a formulação apresentada supõe uma produtividade potencial do capital constante, e, por conseguinte, a medida de produtividade do capital vigente é interpretada como uma medida de utilização da capacidade. 


$$
\mathrm{g}_{\mathrm{s}}=\mathrm{s}_{\mathrm{p}} \pi \mathrm{u}
$$

\subsection{Investimento}

O investimento, apesar de seu papel essencial, possui menor homogeneidade nos modelos pós-keynesianos. Ainda assim, é comum a apresentação de pelo menos três gerações devidamente demarcadas de funções de investimento e, consequentemente, de modelos de crescimento e distribuição. A primeira equação advém do modelo de Robinson (1962) e pode ser apresentada da seguinte forma:

$$
g_{i}=\alpha+\beta r
$$

Nessa equação, a taxa de crescimento do investimento, g, é uma função representada por uma parte autônoma, $\alpha$, frequentemente relacionada aos animal spirits dos capitalistas, e por uma proporção $\beta$ da taxa de lucro, $r$.

Na segunda geração de modelos, destacam-se as contribuições de Dutt (1984) e Rowthorn (1982), que incorporam a taxa de capacidade utilizada apresentando a seguinte equação:

$$
\mathrm{g}_{\mathrm{i}}=\alpha+\beta \mathrm{r}+\gamma \mathrm{u}
$$

Assim, além da taxa de lucro e dos animal spirits, a taxa de crescimento do investimento depende, também, de uma proporção $\gamma$ da taxa de capacidade utilizada, $u$. $O$ grau de capacidade utilizada é a relação produto-capital, considerada exógena na equação 6, o que resultava em plena utilização no modelo de Robinson (1962) e correções apenas via preços no longo prazo. Com a inclusão da taxa de capacidade utilizada na equação, as correções deixam de ocorrer via preços, acontecendo por meio de quantidades.

Por fim, tem-se a contribuição essencial de Bhaduri e Marglin (1990). Segundo eles, a parcela de lucros no produto (profit-share) seria um melhor indicador das decisões de investimento capitalistas do que a taxa de lucro. Isso acontece devido ao fato de que a taxa de lucro pode ser dividida em dois fatores distintos, capacidade utilizada e profit-share, como apresentado anteriormente. Desse modo, uma equação que torne endógena a taxa de capacidade utilizada, mantendo o uso da taxa de lucro, estará acumulando o impacto de utilização da capacidade e, por conseguinte, supervalorizando-o. A equação proposta por Bhaduri e Marglin é a seguinte: 


$$
\mathrm{g}_{\mathrm{i}}=\alpha+\beta \pi+\gamma \mathrm{u}
$$

Pode-se observar que taxa de crescimento do investimento é uma função, assim como nas demais gerações, de uma variável autônoma, $\alpha$, bem como de uma proporção $\beta$, do profit-share, $\pi$, e uma proporção, $\gamma$, do grau de capacidade utilizada, $u$. Desse modo, evita-se o duplo impacto da capacidade utilizada, o que permite ao modelo a incorporação do resultado profit-led, como será observado na sequência.

\subsection{Exportações Líquidas}

Uma vez apresentadas as equações de poupança e investimento, resta apenas a formalização do comportamento do setor externo para a apresentação do modelo aberto. Este pode ser resumido pela equação de exportações líquidas da seguinte maneira:

$$
\mathrm{g}_{\mathrm{nx}}=\sigma \mathrm{e}_{\mathrm{r}}(\pi)-\varphi \mathrm{u}
$$

A taxa de crescimento das exportações líquidas depende do comportamento da demanda, de forma que aumentos da demanda interna aumentam as importações. Desse modo, um crescimento da demanda interna superior ao crescimento da demanda externa implica um efeito negativo na balança comercial, representado por um efeito negativo em relação à taxa de capacidade utilizada, $u$, na equação 9. Além disso, assumindo que a condição de Marshall-lerner se sustente, as exportações líquidas devem sofrer efeitos positivos de desvalorizações da taxa de câmbio real, $\mathrm{e}_{\mathrm{r}}$.

Entretanto, os ganhos de competitividade internacional resultantes de variações na distribuição funcional da renda, como afirmam Hein e Vogel (2008), são dependentes de como ocorrem. ${ }^{11}$ As mudanças via alterações no mark-up da economia têm uma relação inversa com a competitividade internacional. Já uma modificação na distribuição via relação entre custos de trabalho e custos de material, ou se a própria alteração na taxa de câmbio for a causa da redistribuição, existe um efeito direto. Logo, variações no profit-share da economia podem estar associadas tanto a efeitos positivos quanto a negativos na competitividade internacional, o que garante papel importante ao setor externo na determinação do regime de crescimento.

11 Esse caráter de desconhecimento do efeito da distribuição de renda nas exportações líquidas torna uma formalização mais rigorosa - utilizando a formação de preços via mark-up - necessária. Esta, entretanto, é apresentada no Apêndice A, uma vez que o restante do modelo não foi apresentado da mesma forma. 


\subsection{Resultados}

A condição de equilíbrio utilizada nos modelos pós-keynesianos é a igualdade entre poupança e investimento no longo prazo. Logo, tem-se:

$$
\mathrm{S}=\mathrm{I}+\mathrm{NX}
$$

Assim, poupança é igual ao investimento mais o resultado das exportações líquidas, NX. Normalizando a condição de equilíbrio, obtém-se:

$$
\frac{S}{K}=\frac{I}{K}+\frac{N X}{K}
$$

Ou seja,

$$
g_{s}=g_{i}+g_{n x}
$$

Assim, utilizando a equação 5 da taxa de crescimento da poupança juntamente com a equação 8 de crescimento do investimento - relevante para o presente estudo - bem como a equação de crescimento das exportações líquidas e a condição de equilíbrio de longo prazo, obtém-se o seguinte sistema:

$$
\begin{aligned}
& g_{\mathrm{i}}=\alpha+\beta \pi+\gamma \mathrm{u} \\
& \mathrm{g}_{\mathrm{s}}=\mathrm{s}_{\mathrm{p}} \pi \mathrm{u} \\
& \mathrm{g}_{\mathrm{nx}}=\sigma \mathrm{e}_{\mathrm{r}}(\pi)-\varphi \mathrm{u} \\
& \mathrm{g}_{\mathrm{s}}=\mathrm{g}_{\mathrm{i}}+\mathrm{g}_{\mathrm{nx}}
\end{aligned}
$$

Os resultados são:

$$
\begin{gathered}
u^{*}=\frac{\alpha+\beta \pi+\sigma e_{r}(\pi)}{s_{p} \pi+\varphi-\gamma} \\
g^{*}=\alpha+\beta \pi+\gamma \frac{\alpha+\beta \pi+\sigma e_{r}(\pi)}{s_{p} \pi+\varphi-\gamma}
\end{gathered}
$$

A partir deles, é possível observar que as principais propriedades do modelo Bhaduri e Marglin são: a) paradoxo da poupança; c) regimes de crescimento tanto wage quanto profit-led. A primeira propriedade é comum a todos os modelos pós-keynesianos. Aumentos da propensão a poupar reduzem o crescimento 
e a capacidade utilizada das economias. Já a segunda propriedade é exclusiva dos modelos da terceira geração - aqueles que utilizam a função de investimento proposta por Bhaduri e Marglin - e pode ser observada formalmente através das seguintes derivadas:

$$
\begin{gathered}
\frac{d u}{d \pi}=\frac{\left(s_{p} \pi+\varphi-\gamma\right)\left(\beta+\sigma \frac{\partial e_{r}}{\partial \pi}\right)-\left(\alpha+\beta \pi+\sigma e_{r}(\pi)\right) s_{p}}{(s \pi-\gamma)^{2}} \\
\frac{d g}{d \pi}=\beta+\gamma \frac{\partial u}{\partial \pi}
\end{gathered}
$$

A determinação do regime de crescimento das economias depende da magnitude dos parâmetros, visto que a derivada 15 não tem sinal definido. Assim, destaca-se o caráter dual dos salários, que podem ser tanto custo quanto demanda, uma vez que o profit-share varia de forma inversa à taxa de capacidade utilizada para mudanças na proporção dos salários. A inclusão apenas da capacidade utilizada supervaloriza o efeito de demanda dos salários. Bhaduri (2007) define os regimes wage-led e profit-led da seguinte forma:

In a closed economy, any redistribution of income between profits and wages affects aggregate demand through two different channels (custos e consumo) [...]. Depending on which of these two effects dominates quantitatively, two alternative possibilities emerge for demand-led expansion. The case dominated by greater consumption expenditure due to higher real wages and lower profit share is called wage-led, whereas the case dominated by greater investment expenditure due to higher profit share and lower real wages is termed as profit-led. (BHADURI, 2007, p. 148)

\section{A Razoável Harmonia Empírico-Teórica}

Uma vasta quantidade de estudos econométricos já foi realizada para testar os regimes de crescimento de diversos países. É possível encontrar na literatura preferência pelo teste single equation. Ainda assim, existem também testes realizados a partir de modelos de vetores autorregressivos (VAR), assim como por modelos macrodinâmicos. Hartwig (2012) destaca que a maior parte dos estudos se concentra em sete países: Áustria, França, Holanda, Japão, Alemanha, Reino Unido e Estados Unidos. Isso ocorre, principalmente, pela quantidade de dados disponíveis, o que faz com que os países em desenvolvimento sejam menos estudados de forma aplicada. O Brasil, desse modo, possui uma menor quantidade de testes realizados e, por vezes, conta apenas com trabalhos de caráter teórico. O seguinte quadro apresenta os principais resultados encontrados na literatura internacional ${ }^{12}$ :

12 Trabalhos com foco nos regimes de produtividade, com observação dos regimes pelo lado da 
Quadro 1 - Revisão da literatura

\begin{tabular}{|c|c|c|}
\hline \multicolumn{3}{|c|}{ Regimes de crescimento de demanda } \\
\hline & Wage-led & Profit-led \\
\hline Alemanha & $\begin{array}{l}\text { Hein e Vogel (2007), Hein e Vogel } \\
\text { (2008), Naastepad e Storm (2006), } \\
\text { Stockhammer, Hein e Grafl (2007), } \\
\text { Onaran e Galanis (2012) e Bowles e } \\
\text { Boyer (1995). }\end{array}$ & \\
\hline Áustria & & $\begin{array}{l}\text { Hein e Vogel (2008) e Stockham- } \\
\text { mer e Ederer (2008). }\end{array}$ \\
\hline Brasil & Bruno (2003) ${ }^{1}$ e Tomio (2012). & $\begin{array}{l}\text { Araújo e Gala (2012), Bru- } \\
\text { no (2003) e Câmara, Feijó e } \\
\text { Cerqueira (2013). }\end{array}$ \\
\hline China & & $\begin{array}{l}\text { Simarro (2011); Onaran e Galanis } \\
\text { (2012) }\end{array}$ \\
\hline $\begin{array}{l}\text { Coreia do } \\
\text { Sul }\end{array}$ & $\begin{array}{l}\text { Onaran e Stcokhammer (2001) e } \\
\text { Onaran e Galanis (2012). }\end{array}$ & \\
\hline $\begin{array}{l}\text { Estados } \\
\text { Unidos }\end{array}$ & $\begin{array}{l}\text { Hein e Vogel (2008), Onaran, Sto- } \\
\text { ckhammer e Grafl (2011), Onaran } \\
\text { e Galanis (2012) e Bowles e Boyer } \\
\text { (1995). }\end{array}$ & $\begin{array}{l}\text { Barbosa Filho e Taylor (2006) e } \\
\text { Naastepad e Storm (2006). }\end{array}$ \\
\hline França & $\begin{array}{l}\text { Hein e Vogel (2007), Hein e Vogel } \\
\text { (2008), Naastepad e Storm (2006), } \\
\text { Onaran e Galanis (2012) e Bowles e } \\
\text { Boyer (1995). }\end{array}$ & \\
\hline Holanda & $\begin{array}{l}\text { Ederer (2008) e Naastepad e Storm } \\
\text { (2006). }\end{array}$ & Hein e Vogel (2008). \\
\hline Itália & $\begin{array}{l}\text { Naastepad e Storm (2006) e Onaran } \\
\text { e Galanis (2012). }\end{array}$ & \\
\hline Japão & $\begin{array}{l}\text { Onaran e Galanis (2012) e Bowles e } \\
\text { Boyer (1995). }\end{array}$ & Naastepad e Storm (2006). \\
\hline Reino Unido & $\begin{array}{l}\text { Hein e Vogel (2008), Naastepad e } \\
\text { Storm (2006), Onaran e Galanis } \\
\text { (2012) e Bowles e Boyer (1995). }\end{array}$ & Gouvêa e Libânio (2007). \\
\hline Turquia & $\begin{array}{l}\text { Gouvêa e Libânio (2007), Onaran } \\
\text { e Stockhammer (2001) e Onaran e } \\
\text { Galanis (2012). }\end{array}$ & \\
\hline
\end{tabular}

Fonte: Elaboração própria.

oferta, foram preteridos, tais como Hartwig (2012), Naastepad (2005) e Naastepad e Storm (2012), posto que fogem do escopo do trabalho. Da mesma forma, não foram ressaltados os resultados encontrados pela literatura quanto aos regimes de crescimento quando alterado o profit-share de parceiros comerciais (ver ONARAN; GALANIS, 2012) ou resultados relacionados à financeirização (ver HEIN; MUNDT, 2011). A revisão e o presente trabalho se limitaram aos regimes de demanda. 
Tendo em vista os resultados do Quadro 1, observa-se que a maior parte dos trabalhos apresenta resultados wage-led. Os únicos países a não apresentarem esse resultado são China e Áustria. Por outro lado, Turquia, França, Alemanha, Coreia do Sul e Itália apresentam resultados wage-led em todos os estudos analisados. A Alemanha se destaca por possuir o maior número de estudos (seis), os quais apresentam convergência em favor do resultado wage-led. Por fim, podemos observar que, para Estados Unidos, Holanda, Japão e Reino Unido, são encontrados resultados ambíguos, tanto wage-led quanto profit-led. Isso decorre do fato de que tanto métodos quanto períodos analisados são diversos, o que geralmente é determinante para os resultados encontrados. Ainda assim, fica evidente, observando-se o Quadro 1, que a maior parte dos estudos tendem a apresentar resultados wage-led.

Além das estimativas do regime de crescimento total observados no Quadro 1, é possível encontrar na literatura também estimações dos regimes de crescimento domésticos, ou seja, sem considerar o setor externo. Naastepad e Storm (2006) encontram resultados profit-led para Estados Unidos e Japão, assim como Hein e Vogel (2007), para o caso holandês. Entretanto, o resultado doméstico profit-led é bastante incomum nos trabalhos analisados, uma vez que os demais tendem a não apresentá-lo. Desse modo, os trabalhos empíricos afirmam que, do ponto de vista de uma economia fechada, o aumento dos salários é benéfico para o crescimento, como proposto pela teoria.

Ressalta-se, como posto anteriormente, que estudos aplicados não são usualmente realizados para os países em desenvolvimento. Onaran e Stockhammer (2001) e Gouvêa e Libânio (2007) estudam, ambos, o caso da Turquia por meio de modelos VAR, para o qual encontram evidência de uma economia wage-led. Simarro (2011) apresenta evidências de que a China possui um regime de crescimento profit-led. Jetin e Kurt (2011), por sua vez, encontram um resultado profit-led para o caso da Tailândia. Por fim, Onaran e Galanis (2012) aplicam testes para diversos países em desenvolvimento: México, Argentina, Índia, África do Sul, Turquia e China, encontrando comprovação econométrica de que todos esses países possuem regimes de crescimento profit-led.

O caso brasileiro, como o de um país em desenvolvimento, possui também dificuldades de mensuração de seu regime por meio de métodos quantitativos. Nesse sentido, foram encontrados apenas seis trabalhos com testes para a economia brasileira, quais sejam: Bruno (2003), Tomio (2012), Araújo e Gala (2012), Câmara, Feijó e Cerqueira (2013), Oreiro e Araújo (2012) e Oreiro, Abramo e Lima (2013). Os trabalhos analisados apresentam dois tipos de modelos distintos, single equation e macrodinâmicos, e não foram analisadas estimativas através de modelos VAR, como observado na literatura internacional. Os trabalhos aplicados à economia brasileira possuem períodos e métodos consideravelmente 
distintos, dificultando a convergência dos resultados. Além disso, é comum a prática entre os estudos da utilização de proxies e de ajustes nas séries, dada a escassez de dados disponíveis. Naturalmente, não há homogeneidade entre os resultados do regime de crescimento da economia brasileira nos estudos observados. O regime doméstico, entretanto, é recorrentemente referido como wage-led. Assim, a análise dos poucos estudos disponíveis permite a conclusão de que a economia brasileira teria benefícios internos caso fossem implementadas políticas pró-trabalho. No entanto, os efeitos totais - incluindo o setor externo - ainda são inconclusivos.

Os trabalhos analisados são heterogêneos, uma vez que são realizadas para períodos e países distintos com uma variedade de métodos econométricos. Ainda assim, é possível notar três resultados principais: a) economias fechadas tendem a ser wage-led; b) quanto maior o território, maior a chance do país ser wage-led; c) dependência externa, como fonte de demanda, propicia regimes profit-led.

A primeira conclusão é evidente, uma economia fechada não conta com o setor externo e, portanto, não tem benefícios de ganhos de competitividade com reduções salariais. Como as propensões a consumir das classes capitalista e trabalhadora nos países observados tendem a diferir significativamente - sendo a segunda maior que primeira - o aumento dos salários gera crescimento. A segunda e a terceira conclusões estão diretamente relacionadas com a primeira, porque quanto maior o país, maior seu mercado interno e menor sua dependência externa, o que o torna naturalmente mais fechado. Logo, tende a apresentar um regime de crescimento wage-led. Quanto maior a dependência externa, maiores os ganhos de competitividade de reduções salariais, propiciando regimes profit-led. Supõe-se, portanto, que é a dependência externa que faz com que países em desenvolvimento apresentem mais resultados profit-led.

Com isso, existe uma razoável harmonia entre os resultados propostos pelo modelo teórico e os resultados observados nos testes empíricos. Efeitos distintos dos básicos preceitos da teoria kaleckiana são incomuns.

\section{A Econometria do Regime de Crescimento Brasileiro}

De acordo com o método single equation, principal ferramenta de estimação dos regimes de crescimento encontrado literatura internacional, devem ser estimadas equações distintas para os componentes da demanda agregada. Assim, é possível observar separadamente o impacto de variações no profit-share em cada um dos componentes e, posteriormente, somando-as, determinar regime de cres- 
cimento das economias. Desse modo, o método pode ser apresentado formalmente pela soma dos seguintes efeitos parciais, ${ }^{13}$ todos estimados de forma percentual:

$$
\frac{\frac{\partial Y}{Y}}{\partial \pi}=\frac{\frac{\partial C}{Y}}{\partial \pi}+\frac{\frac{\partial I}{Y}}{\partial \pi}+\frac{\frac{\partial N X}{Y}}{\partial \pi}
$$

De acordo com o modelo teórico previamente apresentado, os resultados esperados das equações são os seguintes:

$$
\frac{\frac{\partial C}{Y}}{\partial \pi}<0 ; \frac{\frac{\partial I}{Y}}{\partial \pi}>0 ; \frac{\frac{\partial N X}{Y}}{\partial \pi}=? ; \frac{\frac{\partial Y}{Y}}{\partial \pi}=?
$$

Dadas as suposições quanto às propensões a consumir das classes trabalhadora e capitalista, espera-se que aumento dos lucros implique uma redução do consumo na economia. Já o investimento deve responder positivamente aos aumentos da massa de renda dos capitalistas. O setor externo, como observado anteriormente, pode apresentar resultados tanto positivos quanto negativos a depender da fonte das alterações da redistribuição de renda. Assim, o regime doméstico - definido pela soma entre os efeitos no consumo e investimento - é determinado pela magnitude dos efeitos no consumo e investimento. O regime total, por sua vez, é a soma do resultado doméstico com os efeitos observados do setor externo, que podem tanto reafirmar o resultado doméstico, quanto modificá-lo.

Duas ponderações devem ser feitas quanto ao método single equation. Primeiro, é suposto para a realização do estudo que o wage-share é exógeno, o que pode facilmente ser confrontado, posto que mudanças no nível de emprego ou no mark-up da economia o influenciam. Porém, a endogeneização da parcela dos salários requer o uso de bons instrumentos econométricos, difíceis de serem encontrados para países desenvolvidos e ainda mais raros para o caso de países em desenvolvimento. Segundo, o modelo ignora as evidentes interações entre os componentes da demanda agregada. O uso de métodos como VAR procura evitar essas falhas, porém incorre em uma maior dificuldade de interpretação dos resultados visto a existência de simultaneidade nas equações.

Segundo Hein e Vogel (2008), é possível regredir tanto o wage-share diretamente nas funções dos componentes da demanda agregada, como também incluir as variáveis em nível tanto de lucros quanto de salários. Ambas alternativas foram testadas, todavia apenas aquelas mais significativas serão apresentadas. Além disso, destaca-se que as variáveis são usualmente apresentadas em logarítmicos, isso permite - além de conveniência, dada a redução dos valores estimados

13 O método difere do modelo teórico apresentado, que faz uso de uma equação de poupança. No método econométrico opta-se pela equação de consumo, uma vez que a poupança nada mais é que um resíduo deste (POSSAS, 2001). 
- possíveis correções de crescimentos exponenciais, bem como a estimação dos parâmetros na forma de elasticidades.

O período a ser analisado vai de 1950 a 1994. Desse modo, procura-se observar a o regime de crescimento da economia brasileira antes da implementação efetiva das políticas do plano real. Os dados foram reunidos de Marquetti (2000), ${ }^{14}$ da base de dados do IPEA no ano de 2015 e da Penn World Table 8.1. ${ }^{15}$ Todos os dados são apresentados em valores reais, de forma que as séries de consumo, salários, lucros e resultado da balança comercial foram criadas a partir de suas participações no produto em cada ano. Foi utilizado para a função consumo e investimento dados relativos a 1995, enquanto para as exportações líquidas, dados de relativos a 2013. Quando necessário, foram retirados outliers para corrigir possíveis erros de estimação.

As séries foram testadas para raiz unitária utilizando o teste Dickey-Fuller aumentado (ADF). A maior parte das séries foi constatada como I(1), com apenas a série de balança comercial como proporção do PIB apresentando resultado I(0). Assim, os modelos apresentados foram testados para diferentes formulações, inclusive procurando por evidência de cointegração quando necessário. Os resultados dos testes ADF podem ser encontrados no Anexo A.

\subsection{Consumo}

A equação do consumo foi estimada tendo como base os pressupostos contidos na equação de poupança do modelo teórico. Assim, foi estimado o consumo a partir dos salários e lucros da economia. Todas as variáveis foram deflacionadas usando o deflator do PIB com o objetivo de utilizar apenas valores reais. Além disso, as variáveis foram transformadas em logarítmicos, o que faz com que os parâmetros estimados sejam apresentados na forma de elasticidades. Lembrando o modelo teórico, pressupõe-se que a propensão ao consumo dos trabalhadores é superior a dos capitalistas, portanto espera-se que os aumentos da massa salarial provoquem aumentos do consumo.

As séries de consumo, salários e lucros foram testadas para existência de raiz unitária. Todas apresentaram resultados I(1), assim testes para avaliar a possibilidade de cointegração das variáveis foram realizados. Não foi observada a existência de uma relação de longo prazo entre as variáveis. Por conseguinte, optou-se pela estimação com uso das diferenças das variáveis, como apresentado a seguir:

\footnotetext{
14 Dados obtidos diretamente com o autor. Maiores informações sobre as séries são apresentadas no apêndice de Marquetti (2000).

15 Ver Feenstra, Inklaar, Timmer (2015).
} 


$$
\mathrm{d}(\log (\text { consumo }))=\beta_{0}+\beta_{1} \mathrm{~d}(\log (\text { lucros }))+\beta_{2} \mathrm{~d}(\log (\text { salarios }))
$$

O modelo foi estimado para o período de 1950 a 1992, uma vez que os dados para 1993 e 1994 eram discrepantes em relação ao restante da amostra, o que pode estar relacionado com os insucessos dos planos de estabilização inflacionária do período. A Tabela 1 apresenta os resultados encontrados:

Tabela 1 - Resultados consumo

\begin{tabular}{|c|c|c|c|c|c|c|c|}
\hline \multicolumn{3}{|c|}{ Parâmetros } & \multicolumn{5}{|c|}{ Testes } \\
\hline$\underset{\text { (p-valor) }}{\boldsymbol{\beta}_{0}}$ & $\underset{\text { (p-valor) }}{\beta_{1}}$ & $\begin{array}{c}\beta_{2} \\
\text { (p-valor) }\end{array}$ & $\begin{array}{c}\mathrm{R}^{2} \\
\text { ajustado }\end{array}$ & Ramsey & $\begin{array}{l}\text { Jarque- } \\
\text { Bera }\end{array}$ & White & $\begin{array}{l}\text { Durbin- } \\
\text { Watson }\end{array}$ \\
\hline $\begin{array}{c}-0,012118 \\
(0,0821)\end{array}$ & $\begin{array}{c}0,594691 \\
(0)\end{array}$ & $\begin{array}{c}0,534935 \\
(0)\end{array}$ & 0,7713 & 0,5377 & 0,71 & 0,99 & 2,3689 \\
\hline
\end{tabular}

Fonte: Elaboração própria.

Os parâmetros estimados tanto para os salários quanto para os lucros se mostraram estatisticamente significantes ao nível de $1 \%$, enquanto a constante a $10 \%$. A constante foi mantida observando-se pouca ou nenhuma alteração na equação com sua retirada, não existindo valor estatístico para tal medida. A equação apresentou robustez explicativa, observando-se o valor do $R^{2}$ ajustado, bem como o resultado do teste de Ramsey. Ademais, os testes de autocorrelação, heterocedasticidade e normalidade não apresentaram alterações relevantes.

Observa-se que um aumento de $1 \%$ nos lucros eleva em $0,59 \%$ o consumo, enquanto o mesmo aumento para os salários eleva o consumo em $0,53 \%$, ceteris paribus. Esses resultados contrastam com os resultados encontrados na literatura, assim como com a teoria - visto que não há confirmação da hipótese kaleckiana de propensão a consumir mais elevada da classe trabalhadora. Os parâmetros estimados apresentaram valores bastante próximos. O teste de significância para testar a igualdade entre os parâmetros indica que estatisticamente estes podem não ser distintos, apresentando os mesmos valores ou, até mesmo, valores invertidos. Os intervalos de confiança a 95\% são, portanto, bastante semelhantes. Os lucros apresentam um intervalo de 0,4592 a 0,7391 e os salários, de 0,3455 a 0,7242 .

Nesse sentido, observa-se o primeiro aspecto paradoxal da economia brasileira. Como observado anteriormente, a suposição kaleckiana de propensões a consumir maiores para a classe trabalhadora se confirma na maioria dos casos observados. Essa suposição é, inclusive, responsável pelas evidências, indicando que os regimes domésticos das economias são wage-led. O caso brasileiro contraria as expectativas.

Contudo, é interessante notar que Tavares (1986) e Tavares e Serra (1976), com base no modelo kaleckiano, afirmam que o processo de substi- 
tuição de importações brasileiro teve sucesso nos anos 70 devido a uma forte contribuição do consumo capitalista. Segundo os autores, o crescimento industrial e, consequentemente, o crescimento brasileiro forma sustentados por um gradativo aumento do consumo capitalista, resultante de políticas governamentais e de esforços das próprias firmas de induzirem um aumento de consumo da classe mais abastada. Desse modo, o resultado encontrado com aumento dos lucros impactando de forma superior ao aumento dos salários pode ser uma peculiaridade brasileira, como demonstra a autora.

Em oposição à tese de Tavares, é importante salientar os resultados encontrados por Wells (1977). Enquanto Tavares argumenta que o crescimento foi sustentado majoritariamente pelo consumo da classe capitalista, Wells demonstra, através das pesquisas com consumidores na Grande Rio de Janeiro dos anos 60 e 70, que a classe de trabalhadores, especialmente a classe média, teve papel importante no consumo do período por meio de crédito e redistribuição de renda.

De modo menos específico ao caso brasileiro, é possível levantar como explicação às preocupações dos teóricos do desenvolvimento com a mimetização dos padrões de consumo de países desenvolvidos. Hirschman (1958) e, especialmente Nurkse (1952, 1953), ao resgatar o conceito de "efeito demonstração”, argumentaram que países em desenvolvimento possuem menores taxas de poupança devido à imitação dos padrões de consumo dos países desenvolvidos. O contato com os parâmetros de consumo de países desenvolvidos criaria nos indivíduos a necessidade de consumir bens em qualidade e quantidade ainda não adquiríveis para os níveis de renda de sociedades em desenvolvimento. Isso se apresentaria na forma de uma maior propensão a consumir e menores taxas de poupança. Em um modelo liderado pela oferta, como no caso dos dois autores, essa imitação reduziria a taxa de crescimento dos países.

O objetivo do presente trabalho é apenas apresentar os resultados empíricos sem entrar em detalhes sobre as explicações teóricas. Assim, tendo em vista as possíveis razões apresentadas para a inconclusividade dos resultados e desconsiderando os problemas técnicos quanto à proximidade dos parâmetros, foram utilizados os resultados, mesmo distintos dos teóricos, para calcular o efeito de um aumento do profit-share no produto. O cálculo, como proposto por Hein e Vogel (2008), realizado para transformar as elasticidades encontradas nos parâmetros foi o seguinte:

$$
\frac{\frac{\partial C}{Y}}{\partial \pi}=\beta_{1} \frac{C}{P}-\beta_{2} \frac{C}{W}
$$


Tal que $C, P$ e $W$ são consumo, lucros e salários médios do período analisado, respectivamente. O resultado encontrado para a equação 20 foi -0,1497.

Por conseguinte, pode ser observado que o aumento do profit-share em $1 \%$ reduz o consumo em $0,149 \%$. As elasticidades observadas anteriormente davam a impressão de que aumentos do profit-share seriam benéficos para o crescimento do consumo, porém um aumento dos lucros é igualmente uma redução de salários na forma como foram definidos. Assim, dadas as proporções médias de lucros e salários para o período analisado da economia brasileira (57,2\% para o primeiro e $42,8 \%$ para o segundo), um aumento de $1 \%$ nos lucros gera uma redução de 1,31\% nos salários. A proporção, já favorável aos lucros, eleva-se rapidamente, o que tem um impacto negativo no consumo total, mesmo com as elasticidades maiores dos lucros.

No caso brasileiro, portanto, diferentemente de outros países, a redução de consumo é um efeito de sua distribuição de lucros e salários e não de suas propensões a consumir. ${ }^{16} \mathrm{~A}$ incoerência entre teoria e teste se desfaz em parte, uma vez que é confirmada a hipótese de que aumentos da parcela de lucros da economia reduzem o consumo. Porém, as elasticidades indistintas alertam para as possíveis desarmonias teórico-empíricas brasileiras.

\subsection{Investimento}

A equação de investimento foi estimada de acordo com o modelo teórico, todavia foi utilizado o PIB real - dados do IBGE - como proxy de capacidade utilizada, uma vez que dados desta são de difícil obtenção. Foi utilizada para o investimento a série de formação bruta de capital fixo produtivo (FBCF) de Marquetti (2000) e para a participação dos lucros, a série de profit-share estimada no mesmo trabalho. PIB e FBCF foram transformados em logarítmicos para a obtenção das elasticidades. De acordo com o modelo teórico, espera-se que tanto o aumento do profit-share quanto do produto impliquem aumento do investimento.

As séries foram testadas para a existência de raiz unitária, de forma que todas apresentaram resultados I(1) pelo teste ADF. Entretanto, a série relativa ao profit-share apresentou resultado I(0) quando utilizado o teste Phillippe-Perron. O procedimento de Johansen para testar cointegração indicou a existência de uma relação de longo prazo entre as variáveis. Assim, aceitando os resultados do teste ADF, foi estimado um modelo de correção de erros.

Como consequência, primeiramente foi estimada a equação com os efeitos de longo prazo, em nível. A equação estimada foi a seguinte:

16 Araújo e Gala (2012), por não fazerem a ponderação dos resultados dos parâmetros, correm o risco de ter observado um valor não condizente com a realidade da economia brasileira. 


$$
\log (\mathrm{FBCF})=\alpha_{2} \log (\mathrm{PIB})+\alpha_{3} \text { pshare }
$$

A constante não apresentou resultados significativos em nenhuma das alternativas tentadas. Assim, optou-se por sua retirada do modelo. Os resultados seguem na Tabela 2:

Tabela 2 - Resultados de investimento em nível

\begin{tabular}{ccccccc}
\hline \multicolumn{2}{c}{ Parâmetros } & \multicolumn{5}{c}{ Testes } \\
\hline $\begin{array}{c}\boldsymbol{\alpha}_{2} \\
\text { (p-valor) }\end{array}$ & $\begin{array}{c}\alpha_{3} \\
(\mathrm{p} \text {-valor) }\end{array}$ & $\begin{array}{c}\mathrm{R}^{2} \\
\text { ajustado }\end{array}$ & Ramsey & Jarque-Bera & White & $\begin{array}{c}\text { Durbin- } \\
\text { Watson }\end{array}$ \\
$\mathbf{1 , 2 6 8 6 3 5}$ & $\begin{array}{c}2,521145 \\
(\mathbf{0})\end{array}$ & 0,9886 & 0,3282 & 0,438 & 0,437 & 0,6147 \\
\hline
\end{tabular}

Fonte: Elaboração própria.

De fato, o teste de raiz unitário (ADF) dos resíduos da equação apresentou um resultado I(0), corroborando o resultado encontrado pelo procedimento de Johansen. Com isso, foi possível estimar o seguinte modelo de correção de erros:

$$
\mathrm{d}\left(\log (\mathrm{FBCF})=\beta_{1} \mathrm{~d}(\log (\text { pib }))+\beta_{2} \mathrm{~d}(\text { pshare })+\beta_{3} \varepsilon_{\mathrm{t}-1}\right.
$$

Desse modo, o coeficiente $\beta_{3}$, em função dos resíduos da equação 21 , indica a correção de erro e deve apresentar um resultado negativo. O modelo foi estimado com os dados de 1950 até 1994, porém o ano de 1961 foi retirado da amostra para evitar problemas de heterocedasticidade e não normalidade dos resíduos. A instabilidade política de $1961 \mathrm{fez}$ com que o investimento tivesse um comportamento bastante distinto em relação ao PIB daquele ano. Os resultados do modelo estão apresentados na Tabela 3.

Tabela 3 - Resultados de investimento com correção de erros

\begin{tabular}{cccccccc}
\hline \multicolumn{3}{c}{ Parâmetros } & \multicolumn{5}{c}{ Testes } \\
\hline $\begin{array}{c}\boldsymbol{\beta}_{1} \\
\text { (p-valor) }\end{array}$ & $\begin{array}{c}\beta_{2} \\
\text { (p-valor) }\end{array}$ & $\begin{array}{c}\beta_{3} \\
\text { (p-valor) }\end{array}$ & $\begin{array}{c}\mathrm{R}^{2} \\
\text { ajustado }\end{array}$ & $\begin{array}{c}\text { Ramsey } \\
(4)\end{array}$ & $\begin{array}{c}\text { Jarque- } \\
\text { Bera }\end{array}$ & White & $\begin{array}{c}\text { Durbin- } \\
\text { Watson }\end{array}$ \\
$\mathbf{1 , 4 1 9 4}$ & 1,7505 & $-0,3001$ & 0,6047 & 0,8728 & 0,7692 & 0,1248 & 1,8591 \\
$(\mathbf{0})$ & $(0,01)$ & $(0,007)$ & & & & & \\
\hline
\end{tabular}

Fonte: Elaboração própria.

Os parâmetros estimados apresentaram resultados estatisticamente significativos a $1 \%$. O R $R^{2}$ ajustado foi de 0,6067 e os demais testes de correlação, heterocedasticidade e normalidade não apresentaram problemas. Como esperado, aumentos tanto do profit-share quanto do PIB geram aumentos do investimento. O parâmetro de correção de erro foi negativo, também como suposto. Assim, o 
modelo se mostrou robusto. Para calcular o efeito percentual de uma variação do investimento em função de mudanças no profit-share no produto, foi feita a seguinte transformação:

$$
\frac{\frac{\partial I}{Y}}{\partial \pi}=\beta_{2} \frac{I}{Y}
$$

Tal que I e Y são os valores médios de formação bruta de capital fixo produtivo e do PIB do período, respectivamente. O resultado do cálculo foi igual a 0,2418.

O efeito calculado, como esperado, foi positivo, de forma que um aumento de $1 \%$ no profit-share eleva em $0,24 \%$ o investimento como proporção do PIB. Teoria e teste, neste aspecto, mantiveram-se em sintonia. Comparações com os trabalhos observados para economia brasileira são pouco elucidativas, posto que não apresentaram resultados significativos para o investimento ou utilizaram equações bastante distintas da utilizada neste trabalho. Porém, é possível que os resultados não significativos tenham sido encontrados nos trabalhos que não fizeram a distinção entre formação bruta de capital fixo produtivo e não produtivo. O modelo teórico tem o investimento produtivo como base, de forma que a utilização de dados de formação bruta de capital fixo que façam a inclusão de investimentos em habitação e outros fatores não relevantes perde poder de explicação. Ademais, os períodos analisados, como já ressaltado, não se assemelham, de forma que a comparação se torna pouco útil.

\subsection{Exportações Líquidas}

A última equação estimada foi a de exportações líquidas do país. O resultado da balança comercial como proporção do PIB foi utilizado como variável dependente e essa mesma variável defasada em um período, o profit-share, o PIB mundial e o PIB brasileiro foram utilizados como variáveis explicativas. Como proxy do PIB mundial, foi utilizado o somatório do PIB dos países disponíveis em cada período, obtidos na Penn World Table 8.1. A equação tem como base o trabalho de Hein e Vogel (2008), sendo definida da seguinte forma:

$$
\frac{N X}{P I B}=\beta_{1} \frac{N X(-1)}{P I B(-1)}+\beta_{2} d(\text { pshare })+\beta_{3} d(\log (\text { pibm }))+\beta_{4} d(\log (\text { pib }))
$$

Como a variável explicada apresentou um resultado I(0) quando testada para raiz unitária e as demais variáveis apresentaram resultados I(1), não foi possível estimar modelos de cointegração. O PIB mundial e o PIB brasileiro foram transformados em logarítmicos, linearizando seus crescimentos exponenciais. Espera-se que um aumento do PIB interno reduza as exportações, posto que serve como proxy de capacidade utilizada e, portanto, de demanda por importações. Já um 
aumento do PIB mundial deveria incrementar as exportações líquidas, devido ao aumento de demanda externa. O profit-share, como já destacado, é uma incógnita, podendo apresentar resultados tanto positivos quanto negativos a depender de como ocorrem as variações na distribuição.

Tabela 4 - Resultados das exportações líquidas

\begin{tabular}{ccccccccc}
\hline \multicolumn{4}{c}{ Parâmetros } & \multicolumn{7}{c}{ Testes } \\
\hline $\boldsymbol{\beta}_{1}$ & $\beta_{2}$ & $\beta_{3}$ & $\beta_{4}$ & $\mathrm{R}^{2}$ \\
(p-valor) & $(\mathrm{p}$-valor) & $(\mathrm{p}$-valor) & (p-valor) & ajustado & Ramsey & $\begin{array}{c}\text { Jarque- } \\
\text { Bera }\end{array}$ & White & $\begin{array}{c}\text { Durbin- } \\
\text { Watson }\end{array}$ \\
$\mathbf{0 , 7 2 6 0}(\mathbf{0})$ & $-0,3305$ & 0,2263 & $-0,1685$ & 0,6423 & 0,1364 & 0,1734 & 0,9511 & 1,9337 \\
\hline
\end{tabular}

Fonte: Elaboração própria.

Observa-se que o modelo apresentou bons resultados, com todos os parâmetros estatisticamente significativos a $1 \%$. O $R^{2}$ ajustado apresentou um resultado razoável e os demais testes não apresentaram problemas. Como esperado, o parâmetro $\beta_{3}$ foi positivo e o $\beta_{4}$, negativo. Já o parâmetro relacionado ao profit-share apresentou um resultado negativo. Logo, um aumento da parcela de lucros - redução da parcela de salários - reduz as exportações líquidas. Esse resultado é condizente com variações na parcela de lucros relacionadas a mudanças no mark-up da economia, posto que essas alterações reduziriam a competitividade internacional. ${ }^{17}$

A equação já foi estimada diretamente como proporção do PIB. Desse modo, o parâmetro relacionado ao profit-share apresentaria o impacto como proporção do PIB. Entretanto, a inserção de uma variável defasada faz com que seja necessária a mensuração do impacto do profit-share nos demais períodos, o que torna o impacto calculado uma série geométrica cujo somatório é representado da seguinte forma:

$$
\frac{\frac{\partial N X}{Y}}{\partial \pi}=\frac{\beta_{2}}{1-\beta_{1}}
$$

O resultado obtido no calculo foi igual a $-1,2065$. Ou seja, um aumento do profit-share em $1 \%$ reduz as exportações líquidas como proporção do PIB em $1,2065 \% .{ }^{18} \mathrm{O}$ Brasil, portanto, tem um caso bastante especial quando comparado com os resultados apresentados pelos demais países do mundo. Dada a evidência empírica, em geral espera-se que reduções da parcela salarial gerem aumentos de competitividade e aumentem as exportações líquidas do país. Esse deveria ser o

$17 \quad$ Ver Apêndice A.

18 O resultado negativo para o Brasil foi encontrado também por Tomio (2012) em um teste realizado para os anos de 1956 a 2008, com uma equação bastante semelhante. Além disso, a teoria não descarta a possibilidade desse resultado. 
caso de uma economia em desenvolvimento com setor externo possuidor de papel estratégico em seu crescimento. O resultado brasileiro é oposto ao esperado, as reduções de salários impactam negativamente em suas exportações líquidas. A desarmonia retorna e o alerta das elasticidades mostra a razão de existir.

\subsection{O Paradoxal Regime de Crescimento Brasileiro}

O resultado doméstico do regime de crescimento da economia é o somatório dos resultados encontrados nas equações 20 e 23. Já o resultado total é a soma do resultado doméstico com a equação 25. Ambos estão apresentados na Tabela 5.

Tabela 5 - Regime de crescimento doméstico e total

\begin{tabular}{|c|c|c|c|c|}
\hline$(\partial \mathrm{C} / \mathrm{Y}) / \partial \pi$ & $(\partial \mathrm{I} / \mathrm{Y}) / \partial \pi$ & Resultado doméstico & $(\partial \mathrm{NX} / \mathrm{Y}) / \partial \pi$ & Resultado total \\
\hline$-0,1497$ & 0,24189 & 0,0921 & $-1,2065$ & $-1,1144$ \\
\hline
\end{tabular}

Fonte: Elaboração própria.

O resultado doméstico é, pelo cálculo, profit-led, uma vez que um aumento do profit-share aumenta a renda da economia. Um aumento de $1 \%$ no profit-share aumenta $0,09 \%$ o PIB. O resultado contrasta com boa parte da literatura analisada, na qual o resultado doméstico tende a ser fortemente wage-led como consequência da observação do país em aspecto fechado. Esse resultado brasileiro advém do impacto de aumentos da parcela dos lucros na renda, apesar de negativo, baixo em relação ao consumo. Como observado, as propensões a consumir da classe trabalhadora e capitalista brasileira são bastante semelhantes, diferentemente dos resultados encontrados nos demais países. Isso faz com que reduções da parcela salarial não reduzam fortemente o consumo, que é mantido com base no consumo dos capitalistas. Assim, o Brasil apresenta um resultado interno profit-led.

O resultado total, por sua vez, foi fortemente wage-led. O produto da economia brasileira se reduz em 1,11\% para aumentos de $1 \%$ na parcela de lucros. Assim, poderia de forma simples constatar que o Brasil - um país de grandes proporções - possui um regime de crescimento wage-led, como acontece em diversas outras economias. O resultado wage-led esperado pela teoria, no entanto, ocorreria devido à força do mercado interno, supostamente wage-led frente ao mercado externo. Assim, o resultado brasileiro traz à tona alguns questionamentos: a) por que um país de grandes proporções possui uma estrutura interna profit-led? b) por que o resultado externo do país é negativo para reduções da parcela salarial no produto?

Pode-se levantar, como hipótese, a seguinte explicação para a primeira questão: o processo de substituição de importação, que ocorreu dos anos 30 até o final dos anos 70 e início dos 80 , e sua racionalidade desenvolvimentista, pode ter contribuído para a existência de uma estrutura de gastos peculiar 
na economia brasileira. Primeiramente, como já destacado, as propensões a consumir adquiriram um aspecto incomum, e o país pôde sustentar seu crescimento, especialmente interno, com consumo da classe mais abastada. Isso é resultado, segundo Tavares (1986), de um esforço pensado tanto de governo quanto de empresários durante o período de substituição de importações. Por outro lado, de acordo com os teóricos do desenvolvimento, os padrões de consumo diferenciados podem ser simplesmente um resultado da imitação dos hábitos de gasto dos países desenvolvidos. Dessa forma, não são efeito de política econômica, mas uma característica de economias em desenvolvimento.

Quanto à segunda questão, voltando-se ao modelo teórico pode-se assumir que as mudanças na redistribuição de renda durante o período ocorreram em grande parte via alterações no mark-up da economia brasileira. Um aumento disso implica uma redução da competitividade externa, o que explicaria as deteriorações do resultado externo. Kalecki (1954) lista basicamente quatro fatores determinantes para alterações no grau de monopólio da economia e, consequentemente, no mark-up: a) concentração do mercado; b) marketing; c) poder dos sindicatos; d) nível das despesas gerais. O primeiro, segundo e quarto com efeitos positivos e o terceiro com efeito negativo (BLECKER, 2011). Assim, é necessária uma análise mais profunda desses fatores para determinar as causas das mudanças no mark-up e, em consequência, da distribuição de renda. Nota-se, entretanto, que a suposição feita inicialmente de que o processo de substituição de importações teria sido oligopolizador se encontra entre as alternativas de resposta para piora na competitividade externa, mesmo com reduções da parcela salarial.

\section{Considerações Finais}

A teoria mainstream de crescimento econômico tende a ter seus modelos ancorados na lei de Say. Assim, assume plena capacidade produtiva e distribuição de renda como simples resultado da produtividade marginal do trabalho, o que faz com que seja indiferente quem possui a renda - capitalistas ou trabalhadores. Os modelos kaleckianos, com base no PDE e na distinção das classes sociais e seus comportamentos, mostra que os modelos tradicionalmente utilizados pelo mainstream podem estar ignorando aspectos importantes.

Aceitando a estrutura oligopolizada da economia brasileira, optou-se pela utilização do modelo kaleckiano de crescimento de longo prazo para testar a estrutura da economia brasileira. Ele mostrou um bom encaixe econométrico com o país, dado que as equações estimadas se mostraram estatisticamente significativas (ainda que possam não ter confirmado hipóteses teóricas). As equações de investimento, consumo e exportações líquidas que apresentaram melhor encaixe econométrico foram muito próximas ou exatamente como 
propostas pela teoria. Os resultados foram de uma estrutura interna profit-led e uma estrutura total wage-led. Esses destoam dos resultados observados na revisão da literatura. Entretanto, adaptam-se à estrutura esperada de uma economia que passou por um processo de substituição de importações, como a brasileira.

O resultado interno provém das alterações nas propensões a consumir da classe capitalista. Já o resultado total, como observado no modelo teórico, acontece devido a alterações no mark-up da economia. Indiferentemente das razões pelas quais o país apresentou tais estruturas no período analisado, cabe destacar que são condizentes tanto com os fatos históricos quanto com a teoria. Entretanto, essas supostas explicações quanto aos resultados encontrados precisam de maior investigação. Mudanças nas características de consumo das classes são incomuns, e afirmar que o processo de substituição de importações foi o responsável pode ser precipitado. Além disso, evidencia-se que foram as alterações no mark-up da economia que estiveram por trás do resultado wage-led, porém não foi parte do escopo deste trabalho identificar quais fatores o modificaram. Ressalta-se apenas que um mercado oligopolizado apresenta um mark-up mais elevado. Essa característica brasileira, todavia, foi tomada como hipótese para a realização do trabalho.

Conclui-se que o regime de crescimento brasileiro pré-Plano Real é, no mínimo, peculiar, considerando-se o período analisado. Primeiro, suas propensões a consumir não são estatisticamente distintas e, portanto, não confirmam a hipótese kaleckiana. Segundo, o Brasil contraria as expectativas tanto no que diz respeito ao regime de crescimento doméstico - uma vez que é um país de grande extensão territorial com um regime profit-led doméstico -, quanto ao que se trata do regime de crescimento total - apresentando um resultado wage-led. Finaliza-se com o entendimento de que o regime de crescimento brasileiro entre 1950 e 1994 é um paradoxo em meio às evidências existentes.

\section{Referências}

ARAÚJO, E.; GALA, P. Regimes de crescimento econômico no Brasil: evidências empíricas e implicações de política. Estudos Avançados, São Paulo, v. 26, n. 75, p. 41-56, 2012.

BARBOSA-FILHO, N.; TAYLOR, L. Distributive and demand cycles in the US economy: a structuralist Goodwin model. Metroeconomica, n. 57, v. 3, p. 389-411, 2006.

BERTELLA, M. A. Modelos de crescimento kaleckianos: uma apreciação. Revista de Economia Política, São Paulo, v. 27, n. 2 (106), p. 209-220, 2007.

BHADURI, A. On the dynamics of profit-led and wage-led growth. Cambridge Journal of Economics, 32, p. 147-160, 2007.

BHADURI, A.; MARGLIN, S. Unemployment and the real wage: the economic basis of contesting political ideologies. Cambridge Journal of Economics, v. 14, n. 4, p. 375-393, 1990. 
BIELSCHOWSKY, R. Estratégia de desenvolvimento e as três frentes de expansão no Brasil: um desenho conceitual. Economia e Sociedade, Campinas, v. 21, número especial, p. 729747, 2012.

BLECKER, R.A. Open economy models of growth and distribution. In: HEIN, E.; STOCKHAMMER, E. (Ed.). A modern guide to keynesian macroeconomics and economic policies. Cheltenham, UK: Edward Elgar, 2011. p. 215-239.

BOWLES, S.; BOYER, R. Wages, aggregate demand, and employment in an open economy: an empirical investigation. In: EPSTEIN, G.; GINTIS, H. (Ed.). Macroeconomic policy after the conservative era: studies in investment, saving and finance. Cambridge: Cambridge University Press, 1995. p. 143-171.

BRESSER-PEREIRA, L. C. A taxa de câmbio no centro da teoria do desenvolvimento. Estudos Avançados, São Paulo, v. 26, n. 75, p. 7-28, 2012.

BRUNO, M. Regimes de crescimento, mudanças estruturais e distribuição na economia brasileira (1970-2001). In: ENCONTRO NACIONAL DE ECONOMIA POLÍTICA, 8., 2003, Florianópolis. Anais[...] Florianópolis: SEP, 2003.

CÂMARA, F.; FEIJÓ, C.; CERQUEIRA, L. F. Distribuição e crescimento em uma economia fechada e com alta inflação: o caso brasileiro pós II guerra. Rio de Janeiro: IPEA, 2013. (Textos para discussão)

DUTT, A. K. Stagnation, income distribution and monopoly power. Cambridge Journal of Economics, v. 8, n. 1, p. 25-40, 1984.

EDERER, S. Competition-oriented wage policy and its effects on aggregate demand in the Netherlands. Working Paper, WIFO, n. 312, 2008.

FEENSTRA, R. C.; INKLAAR, R.; TIMMER M. P. The next generation of the Penn world table. American Economic Review, v. 105, n. 10, p. 3150-3182, 2015.

FONSECA, P. Desenvolvimentismo: a construção do conceito. presente e futuro do desenvolvimento brasileiro. Rio de Janeiro: IPEA, 2015.(Texto para discussão, n. 2103).

GOUVÊA, R. R.; LIBÂNIO, G. A. Demanda efetiva, conflito distributivo e regime de acumulação em um modelo estruturalista de ciclo: os casos britânico e turco. Belo Horizonte: CEDEPLAR/ UFMG, 2007. (Textos para discussão)

HARTWIG, J. Distribution and growth in demand and productivity in Switzerland (19502010). Working Papers, KOF, n. 323, 2012.

HEIN, E. Distribution and growth after Keynes: a post-Keynesian guide. Cheltenham: Edward Elgar, 2014. p. 551.

HEIN, E.; MUNDT, M. Financialisation and the requirements and potentials for wage-led recovery: a review focusing on the G20. Geneva: International Labour Office, 2011. (Conditions of work and employment, n. 37). 
HEIN, E.; VOGEL, L. Distributions and growth in France and Germany: single equation estimations and model simulations based on the Bhaduri/Marglin model. Working Paper, $\mathrm{n}$. 4, Dusseldorf, 2007.

HEIN, E.; VOGEL, L. Distribution and growth reconsidered: empirical results for six OECD countries. Cambridge Journal of Economics, Cambridge, v. 32, n. 3, p. 479-51 1, 2008.

HIRSCHMAN, A. O. The strategy of economic development. New Haven: Yale University Press, 1958.

JETIN, B.; KURT, O. Functional income distribution and growth in Thailand: single equation estimations based on Bhaduri/Marglin model. In: ANNUAL CONFERENCE OF THE RESEARCH NETWORK MACROECONOMICS AND MACROECONOMICS POLICIES, 2011, Berlin.

KALECKI, M. Theory of economic dynamics. London: Unwin, 1954.

LAVOIE, M. Post-Keynesian economics: new foundations. Cheltenham: Edward Elgar Pub, 2015. p. 680.

LAVOIE, M.; STOCKHAMMER, E. Wage-led growth: concept, theories and policies. Geneva: International Labour Office, 2012. (Conditions of work and employment, n. 41).

LUCAS, R. E. Econometric policy evaluation: a critique. In: BRUNNER, K.; MELTZER, A. (Ed.). The Phillips curve and labor markets, Amsterdam: North-Holland, 1976. p. 19-46. (Carnegie-Rochester Conference Series on Public Policy, v. 1)

MARQUETTI, A. A estimativa do estoque de riqueza tangível no Brasil, 1950-1998. Nova Economia, v. 10, n. 2, p. 11-37, 2000.

MOLLO, M. L. R.; AMADO, A. M. O debate desenvolvimentista no Brasil: tomando partido. Economia e Sociedade, [S.1.], v. 24, n. 1, p. 1-28, 2015.

NAASTEPAD, R. Technology, demand and distribution: a cumulative growth model with an application to the Dutch productivity slowdown. Cambridge Journal of Economics, v. 30, n. 3, p. 403-434, 2005.

NAASTEPAD, C.W.M.; STORM, S. OECD demand regimes (1960-2000). Journal of PostKeynesian Economics, v. 29, n. 2, p. 211-246, 2006.

NURKSE, R. Problems of capital formation in underdeveloped countries. New York: Oxford University Press, 1953.

NURKSE, R. Some international aspects of the problem of economic development. The American Economic Review, v. 42, n. 2, p. 571-583, 1952.

ONARAN, O.; GALANIS, G. Is aggregate demand wage-led or profit-led? Geneva: International Labour Office, 2012. (Conditions of work and employment, n. 40)

ONARAN, O.; STOCKHAMMER E. Two different export-oriented growth strategies: under a wage-led accumulation regime. Working Paper Series, PERI, n. 38, 2001. 
ONARAN, Ö.; STOCKHAMMER, E.; GRAFL, L. The finance-dominated growth regime, distribution, and aggregate demand. US Cambridge Journal of Economics, n. 35, v. 4, p. 637661, 2011.

OREIRO, J. L.; ABRAMO, L. D.; LIMA, P. G. C. Taxa de câmbio, taxa de juros e regimes de acumulação em um modelo macro-dinâmico pós-keynesiano: teoria e evidência para o caso brasileiro. In: ENCONTRO INTERNACIONAL DA ASSOCIAÇÃO KEYNESIANA BRASILEIRA, 6., 2013, Vitória. Anais [...]. Vitória: UFES, 2013.

OREIRO, J. L.; ARAÚJO, E. A economia política da desvalorização cambial: teoria e aplicação ao caso brasileiro. In: FORUM DE ECONOMIA DE SÃO PAULO, 9., 2012, São Paulo.

PALLEY, T. Rethinking wage vs profit-led growth theory with implications for policy analysis. Hans Boeckler Foundation: IMK Working Paper, n. 141-2014, 2014.

POSSAS, M. L. Demanda efetiva, investimento e dinâmica: a atualidade de Kalecki para a teoria macroeconômica. In: POMERANZ, L.; MIGLIOLI, J.; LIMA, G. T. Dinâmica Econômica do capitalismo contemporâneo: homenagem a M. Kalecki. São Paulo: EDUSP, 2001.

ROBINSON, J. Essays in the theory of economic growth. London: Macmillan, 1962.

ROWTHORN, B. Demand, real wages and economic growth. Studi Economici, v. 18, p. 3-53, 1982.

SERRANO, F. Long period effective demand and the Sraffian supermultiplier. Contributions to Political Economy, v. 14, p. 67-90, 1995.

SIMARRO, R. M. Functional distribution of income and economic growth in the chinese economy, 1978-2007. Working Papers, n. 168, 2011.

SKOTT, P. Conflict and effective demand in economic growth. Cambridge: Cambridge University Press, 1989.

SKOTT, P. Weaknesses of "wage-led growth". Review of Keynesian Economics, v. 5, n. 3, p. 336-359, 2017.

STOCKHAMMER, E. Robinsonian and kaleckian growth. An update on post-Keynesian growth theories. Working Paper, Viena, n. 67, 1999.

STOCKHAMMER, E.; EDERER, S. Demand effects of the falling wage-share. Empirica, Austria, n. 35, p. 481-502, 2008.

STOCKHAMMER, E.; HEIN, E.; GRAFL, L. Globalization and the effects of changes in functional income distribution on aggregate demand in Germany. Working Paper, Viena, $\mathrm{n}$. $114,2007$.

TAVARES, M.C. Acumulação de capital e industrialização do Brasil. Campinas: UNICAMP, 1986. 
TAVARES, M. C.; SERRA, J. Além da estagnação. In: TAVARES, M. C. Da substituição de importações ao capitalismo financeiro: ensaios sobre economia brasileira. 5. ed. Rio de Janeiro: Zahar, 1976.

TOMIO, B. T. Understanding the brazilian economic growth regime: a Kaleckian approach. In: ENCONTRO INTERNACIONAL DA ASSOCIAÇÃO KEYNESIANA BRASILEIRA, 5., 2012, São Paulo.

WELLS, J. Growth and fluctuations in the Brazilian manufacturing sector during the 1960's and early 1970's. Tese (Ph.D.) - University of Cambridge, 1977.

\section{Apêndice A}

O caráter de dubiedade quanto aos efeitos de mudanças na distribuição de renda nas exportações líquidas obriga uma formalização mais rigorosa. Assim, a formalização que aqui segue está embasada no princípio de formação de preços em um mercado oligopolizado encontrado por Kalecki (1954) para uma economia fechada. Porém, por se tratar de um mercado aberto, foi mais bem formulada por Blecker (1989) e Bhaduri e Marglin (1990), com uma síntese - que servirá como base para este apêndice - apresentada por Hein (2014). Blecker (2011) ressalta que não existe incongruência em utilizar a teoria de Kalecki de forma ampliada para um mercado global, inclusive argumenta que Kalecki teria dado os primeiros insights para as formulações seguintes.

Segundo Kalecki (1954), os preços são formados com base em um markup em relação aos custos do trabalho e o preço dos insumos. Assim, denotando $m$ como o mark-up das firmas, determinado pelo grau de monopólio do mercado, $\mathrm{w}$ como salários nominais, $v$ como a relação trabalho-produto $0, p_{e}$ na qualidade de preços dos bens importados na moeda externa, $e$ na forma de taxa de câmbio e $a$ como preços dos insumos, temos:

$$
\mathrm{p}=(1+\mathrm{m})\left(\mathrm{wv}+\mathrm{p}_{\mathrm{e}} \text { ea }\right)
$$

Por conseguinte, assumindo que a relação entre insumos e salários é observa-se que:

$$
\mathrm{p}=(1+\mathrm{z}) \mathrm{wv}(1+\mathrm{m})
$$

Logo, sabendo que $\Pi=\mathrm{pY}=(1+\mathrm{z})(1+\mathrm{m}) \mathrm{W}$ tal que $\mathrm{W}=\mathrm{Lw}$ nota-se que o profit-share pode ser apresentado da seguinte maneira:

$$
\pi=\frac{\Pi}{\Pi+W}=\frac{(1+z)(1+m)}{(1+z)(1+m)+1}=\frac{1}{1+\frac{1}{(1+z)(1+m)}}
$$


O profit-share, portanto, é determinado pelo mark-up e pela relação entre o custo dos insumos importados e os custos unitários de trabalho. Assim, utilizando a taxa de câmbio real como indicador de competitividade externa, tem-se:

$$
e_{r}=\frac{e p_{e}}{p}
$$

Com relação às taxas de crescimento:

$$
\dot{e}_{r}=\dot{e}+\dot{p}_{e}-\dot{p}
$$

Portanto, evidencia-se o papel da taxa de câmbio na competitividade internacional, uma vez que aumentos da taxa de câmbio nominal aumentam a taxa de câmbio real. Então, juntando as equações 26 com a equação 29, como propõe Hein (2014), observamos três resultados possíveis.

Primeiramente, se a mudança da distribuição for causada por alterações no mark-up, observa-se uma relação inversa entre o profit-share e a competitividade externa. Formalmente:

$$
\frac{\partial e_{r}}{\partial m}=\frac{-e p_{e}\left(w v+p_{e} e a\right)}{p^{2}}<0
$$

Segundo, se uma mudança na taxa de câmbio nominal for a causa da redistribuição de renda, obtém-se uma relação positiva, como segue:

$$
\frac{\partial e_{r}}{\partial e}=\frac{p-(1+m) a e p_{e}}{p^{2} / p_{e}}>0
$$

Por fim, se a fonte das alterações na redistribuição de renda for na mudança da relação entre o preço dos insumos importados e os custos unitários de trabalho, tem-se também uma relação positiva entre profit-share e competitividade internacional, observada a seguir:

$$
\frac{\partial e_{r}}{\partial w}=\frac{e p_{e}(1+m) a}{p^{2}}<0
$$




\section{Anexo A}

\begin{tabular}{|l|c|c|c|}
\hline \multicolumn{3}{|c|}{ Teste Dickey-Fuller aumentado } & \multirow{2}{*}{ Resultado } \\
\cline { 2 - 3 } \multirow{2}{*}{ Variáveis em logaritmos } & \multicolumn{2}{|c|}{ p-valor } & $\mathrm{I}(1)$ \\
\cline { 2 - 3 } & Nível & Primeira diferença & $\mathrm{I}(1)$ \\
\hline consumo & $0,9722^{1}$ & 0,0002 & $\mathrm{I}(1)$ \\
\hline fbcf & $0,9574^{1}$ & 0,0001 & $\mathrm{I}(1)$ \\
\hline lucros & $0,9967^{1}$ & 0 & $\mathrm{I}(1)$ \\
\hline pib & $0,9677^{1}$ & 0,0083 & $\mathrm{I}(1)$ \\
\hline pshare* & $0,2873^{2}$ & 0,0143 & $\mathrm{I}(0)$ \\
\hline salários & $0,9682^{1}$ & 0,0004 & $\mathrm{I}(1)$ \\
\hline bc/pib* & $0,0101^{3}$ & - & \\
\hline pibm & $0,4679^{1}$ & 0 & \\
\hline
\end{tabular}

Fonte: Elaboração própria.

Nota: ${ }^{1}$ teste com tendência e intercepto; ${ }^{2}$ teste com tendência; ${ }^{3}$ teste sem tendência ou intercepto; * variáveis em nível.

Recebido em: 09/06/2017.

Aceito em: 18/09/2018.

\section{(c) BY}

